\title{
LIPOSSOMAS: A BALA MÁGICA ACERTOU?
}

\author{
Nuno C. Santos* \\ Instituto de Bioquímica/Instituto de Medicina Molecular, Faculdade de Medicina de Lisboa, Av. Prof. Egas Moniz, 1649-028 \\ Lisboa - Portugal \\ Miguel A. R. B. Castanho \\ Departamento de Química e Bioquímica, Faculdade de Ciências da Universidade de Lisboa, Campo Grande C8, 1749-016 Lisboa \\ - Portugal e Centro de Química Física Molecular, Complexo I, Instituto Superior Técnico, Av. Rovisco Pais, 1049-001 Lisboa - \\ Portugal
}

Recebido em 15/2/02; aceito em 10/4/02

\begin{abstract}
LIPOSOMES: HAS THE MAGIC BULLET HIT THE TARGET? Efficient drug delivery systems are as important as drug themselves. A powerful drug unable to reach the target cell is useless in practice. Ehrlich's Magic Bullet was the first carrier system to be proposed. The evolution in this domain has been quite slow as the natural mechanisms of mammals against foreign products are hard to overcome. However, lipid-based systems (liposomes and related vesicles) have attained reasonable success. The basic preparations and structural features of liposomes and related vesicles as well as their applications are addressed from the chemist's and biochemist's point of view.
\end{abstract}

Keywords: liposome; vesicle; drug delivery.

\section{INTRODUÇÃO}

Ao longo dos tempos, a utilização da maioria dos compostos terapêuticos tem sido sempre limitada pela impossibilidade de aumento da sua dosagem. A retenção ou degradação do agente terapêutico, baixa solubilidade e, em especial, os efeitos colaterais perniciosos inerentes à sua utilização em concentrações elevadas, tornam muitas vezes difícil a utilização da dosagem necessária para que este cumpra a sua função. Este problema levou a que, durante o século XX, e em especial no decorrer das últimas décadas, tenha sido levado a cabo um grande esforço no sentido de desenvolver um sistema capaz de transportar um composto terapêutico (drogas, em especial as dirigidas a tumores, antibióticos, enzimas, hormonas, agentes quelantes ou compostos modificadores da célula) até um alvo específico (órgão, tecido ou célula).

A primeira proposta de um sistema direccionado de transporte de fármacos data do início do século $\mathrm{XX}^{1}$, quando Paul Ehrlich propôs o seu modelo, que ficou conhecido por "Bala Mágica de Ehrlich" (Ehrlich's Magic Bullet). Neste modelo, o fármaco é ligado ao transportador direccionado, e idealmente exibirá a sua actividade farmacológica apenas no tecido alvo (mecanismos de especificidade, como a ligação entre antigénio e anticorpo, eram já conhecidos). Assim, os efeitos indesejáveis resultantes da sua acção em outros tecidos são largamente diminuídos, enquanto o aumento da eficiência permite o decréscimo da dose administrada. Porém, por mais atractivos e simples que possam parecer os conceitos de Ehrlich, são muito poucos os sucessos até agora obtidos ${ }^{2,3}$.

As primeiras tentativas para a obtenção de um sistema transportador eficaz tiveram como base o encapsulamento das biomoléculas a transportar em vesículas de nylon e outros polímeros sintéticos ${ }^{4-6}$. Contudo, esta abordagem mostrou-se totalmente inadequada, visto estas vesículas de material artificial se acumularem no organismo.

O primeiro grande passo em frente nesta área deu-se em 1965, com a publicação por Alec Bangham e colaboradores de um traba-

*e-mail: nsantos@fm.ul.pt lho de investigação fundamental acerca da difusão de iões através de membranas lipídicas artificiais, embora sem qualquer ligação imediata aos estudos de sistemas transportadores de fármacos ${ }^{7}$. Neste trabalho foi feita a caracterização de um sistema de vesículas fosfolipídicas ao qual, três anos mais tarde, seria dado o nome de lipossomas ${ }^{8}$. No entanto, estas estruturas multilamelares obtidas da hidratação de fosfolípidos já eram anteriormente conhecidas, sendo denominadas "figuras de mielina". Imediatamente após o trabalho de Bangham, os lipossomas impuseram-se como um sistema modelo simples para o estudo de membranas biológicas. O sucesso na incorporação de enzimas em lipossomas ${ }^{10}$ despertou também o interesse da comunidade científica para a sua aplicação médica e farmacológica. Em 1971, Gregory Gregoriadis propôs pela primeira vez a utilização dos lipossomas como sistema transportador de fármacos ${ }^{11}$, mantendo desde então um papel preponderante no desenvolvimento desta área.

Os lipossomas são um caso flagrante de um sistema que teve uma passagem extremamente rápida do campo da investigação para a aplicação comercial (especialmente na área da cosmética), sem mesmo as suas propriedades e eficácia estarem completamente estudadas $^{12}$. Este facto ficou a dever-se, fundamentalmente, à euforia desencadeada na década de 70 e início da década de 80 pelo potencial de aplicação dos lipossomas nas industrias médica e farmacêutica, o que veio mesmo a lançar sérias dúvidas sobre o rigor de alguns resultados da altura ${ }^{13}$.

Nos anos seguintes e até aos nossos dias, com a mesma finalidade, foi também estudada a aplicação de niossomas, nanopartículas, co-polímeros, lipoproteínas, emulsões, lectinas, hormonas, péptidos, anticorpos, e sistemas mais complexos como vírus e eritrócitos, no desenvolvimento de um transportador específico ${ }^{14,15}$. O objectivo de todos estes transportadores é aumentar o potencial terapêutico de um composto, impedindo que este se perca no trajecto para um alvo específico, evitando simultaneamente a ocorrência de efeitos secundários nocivos noutra parte do organismo. Contudo, até hoje, nenhum sistema estudado conseguiu cumprir eficazmente este objectivo, de modo a ser largamente aceite pela indústria farmacêutica. 


\section{LIPOSSOMAS CONVENCIONAIS}

\section{Estrutura}

Como seria de esperar, os lipossomas têm sido o tema de inúmeros artigos de revisão, quer em termos gerais ${ }^{13,16-19}$, quer focados especialmente nas suas propriedades físicas ${ }^{20-24}$, preparação $\mathrm{o}^{25-28}$, mecanismos de formação e fusão ${ }^{29,30}$, gradientes de $\mathrm{pH}$ e transporte de membrana $^{31}$, métodos de caracterização ${ }^{32,33}$, aplicação genérica em Medicina $^{34,35}$, utilização como transportadores ${ }^{36-40}$, técnicas de encapsulamento de agentes bioactivos ${ }^{41}$, interacção com células ${ }^{42}$, utilização em vacinas ${ }^{43}$, aplicações veterinárias ${ }^{44}$, utilização em substituição de eritrócitos ${ }^{45,46}$ ou aplicações cosméticas ${ }^{12}$; incluindo algumas revisões em língua portuguesa ${ }^{47-49}$.

Os lipossomas podem ser definidos como associações coloidais de lípidos anfipáticos, que se organizam espontaneamente em estruturas fechadas tipo concha esférica. Podem ser preparados a partir de misturas lipídicas naturais extraídas e purificadas, ou a partir de lípidos sintéticos, disponíveis comercialmente. Conforme é indicado na Figura 1, os lipossomas podem ser classificados em termos de tamanho, número de lamelas (e sua posição relativa), constituição lipídica (o que também condiciona a sua carga), estabilidade e modo de preparação ${ }^{18}$.

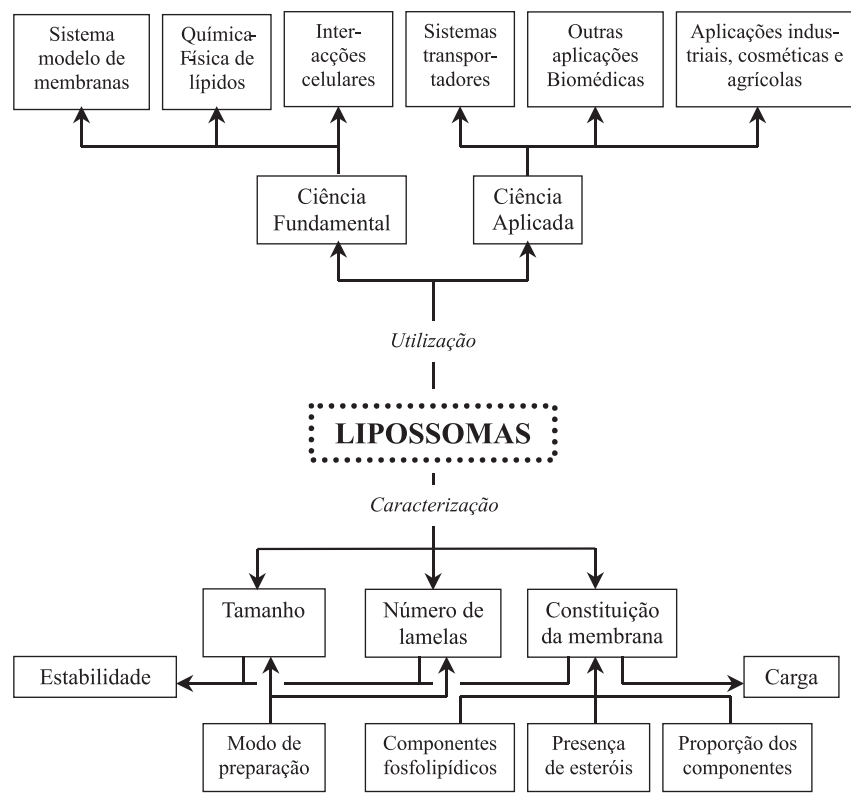

Figura 1. Esquema representativo das várias utilizações dos lipossomas e inter-relação entre os diversos parâmetros que os caracterizam. Adaptado de ref. 18

Durante muito tempo, a classificação estrutural dos vários tipos de lipossomas esteve rodeada de uma grande falta de uniformização e coerência, o que originou alguma confusão na literatura desta área. Devido, em parte, à falta de uma correcta caracterização das diversas estruturas, o tipo de lipossoma era indicado pelo seu processo de preparação (e.g., sonificação, congelação e descongelação, evaporação em fase reversa), pelo nome do investigador que caracterizou pela primeira vez o seu processo de preparação (e.g., "Banghamossomas", "Huangomossomas") ou simplesmente omitido ${ }^{18}$.

A partir do início da década de 80, foi definitivamente adoptada uma nomenclatura para os lipossomas baseada no seu número de bicamadas lipídicas (lamelas) e tamanho ${ }^{25}$. Assim, para os lipossomas de preparação mais imediata, utilizados em todos os primeiros estu- dos, ficou consagrado o nome de vesículas multilamelares ou MLV ("multilamellar vesicles"). Como o nome indica, estas vesículas são constituídas por várias bicamadas lipídicas, aproximadamente concêntricas, podendo o seu diâmetro variar entre 400 e $3500 \mathrm{~nm}^{36}$.

Para muitas das aplicações dos lipossomas, torna-se importante a utilização de um sistema de interpretação mais simples e melhor definido em termos estruturais. Deste modo, em grande parte dos estudos, os MLV são preteridos em favor de lipossomas unilamelares. Destes lipossomas, os mais utilizados são as vesículas unilamelares grandes ou LUV ("large unilamellar vesicles"), de diâmetro superior a $100 \mathrm{~nm}$, bem como as vesículas unilamelares pequenas ou SUV ("small unilamellar vesicles"), com diâmetro entre 20 e $50 \mathrm{~nm}^{18}$. Para além destas vesículas unilamelares, devem-se ainda considerar as vesículas unilamelares gigantes ou GUV ("giant unilamellar vesicles"), com dimensões superiores a $1 \mu \mathrm{m}$, podendo chegar às dezenas de $\mu m^{50}$, tamanho comparável ao de uma célula eucariota. Alguns autores definem ainda uma classe de vesículas unilamelares médias ou MUV ("medium-sized unilamellar vesicles"), com dimensões compreendidas entre os SUV e os LUV'18. De menor importância, mas também caracterizados ${ }^{50}$, encontram-se os lipossomas multivesiculares ou MVL ("multivesicular liposomes") e as vesículas oligolamelares ou OLV ("oligolamellar vesicles") que, à semelhança das unilamelares, podem ser subdivididas em pequenas, grandes e gigantes (SOV, LOV e GOV). Na Figura 2 pode-se observar uma representação esquemática comparativa dos vários tipos de lipossoma.
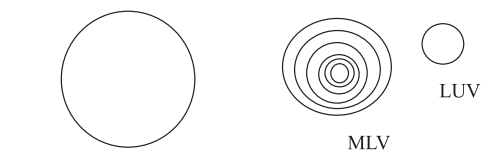

$\mathrm{O}_{\text {SUV }}$

GUV

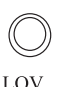

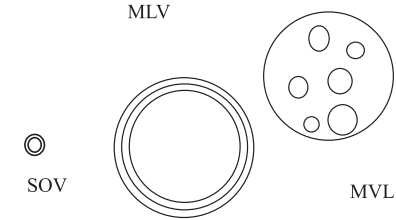

GOV
Figura 2. Representação esquemática dos vários tipos de lipossoma, mostrando a base da sua classificação em termos de tamanho, número de lamelas e sua posição relativa em: Vesículas multilamelares (MLV), vesículas unilamelares pequenas (SUV), vesículas unilamelares grandes (LUV), vesículas unilamelares gigantes (GUV), lipossomas multivesiculares (MVL), vesículas oligolamelares pequenas ( $\mathrm{SOV}$ ), vesículas oligolamelares grandes (LOV) e vesículas oligolamelares gigantes (GOV). Cada linha representa uma bicamada lipídica (lamela). Adaptado de ref. 16

Para além do tamanho e número de lamelas, o outro factor essencial para a caracterização de um lipossoma prende-se com a constituição das bicamadas lipídicas. A composição fosfolipídica, a presença de esteróis, a proporção destes componentes e a inserção de outras moléculas nas bicamadas, vão condicionar vários parâmetros da membrana e do próprio lipossoma; nomeadamente, a sua carga, estabilidade, curvatura da(s) bicamada(s), fase da membrana e formação de domínios lipídicos ${ }^{51}$.

\section{Preparação}

A larga aceitação da utilização de lipossomas para os mais diversos fins (Figura 1) criou a necessidade de desenvolver métodos preparativos eficientes, reprodutíveis e com a simplicidade possível, à escala laboratorial e industrial. Este último encontra-se fora do âmbito deste artigo, que se irá igualmente cingir à preparação dos siste- 
mas de vesículas lipídicas mais utilizados: MLV, SUV e LUV (para revisão dos processos de preparação de lipossomas ver, e.g., ref. 18 e 25-28). A preparação destes três tipos de suspensão lipídica é descrita sumariamente na Figura 3.

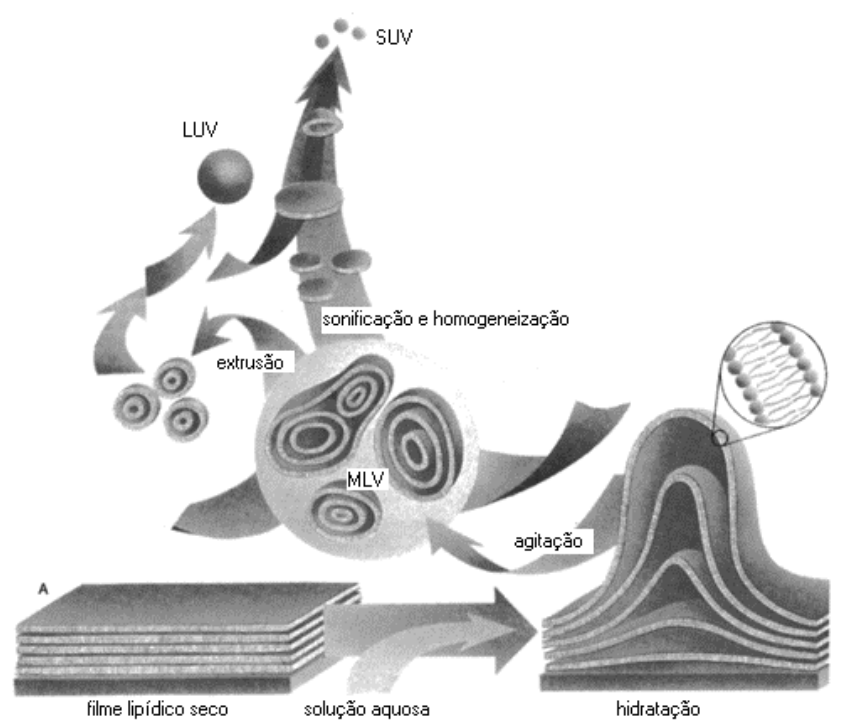

Figura 3. Representação esquemática das metodologias de preparação de vesículas multilamelares (MLV), vesículas unilamelares pequenas (SUV) e vesículas unilamelares grandes (LUV). Ver texto para descrição destas metodologias. Adaptado de www.avantilipids.com

O tipo de lipossoma é, essencialmente, condicionado pelo seu método de preparação. Assim, visto a composição química, número de camadas, distribuição de tamanhos, número de lamelas e o volume encapsulado influenciarem consideravelmente qualquer aplicação dos lipossomas, o seu método de preparação deverá ser sempre escolhido criteriosamente. De um modo geral, a preparação de vesículas lipídicas pode ser dividida em três fases consecutivas: preparação das fases aquosa e lipídica, hidratação do lípido e ainda, para a maioria dos sistemas, um processamento secundário, necessário para a obtenção do produto final ${ }^{27}$.

Os MLV são os lipossomas de mais fácil preparação, e por isso os primeiros a terem sido caracterizados. Foi este o sistema utilizado em todos os primeiros trabalhos ${ }^{7,8,11}$, mantendo uma larga aceitação na actualidade $^{52,53}$. Após a escolha da composição lipídica e solução aquosa a utilizar (usualmente uma solução tampão), de acordo com o objectivo pretendido, cada lípido (seco) deverá ser dissolvido num solvente ou mistura de solventes orgânicos que seja, simultaneamente, eficiente na dissolução da concentração de lípido pretendida e suficientemente volátil (e.g., clorofórmio, misturas clorofórmio-metanol). Atendendo ao volume, concentração e proporção dos componentes da suspensão de vesículas pretendida, os volumes adequados das soluções de cada componente devem ser adicionados num balão de fundo redondo. $\mathrm{O}$ solvente orgânico é evaporado até à secura sob fluxo de azoto, rodando o balão de modo a formar um filme lipídico tão fino quanto possível. De forma a eliminar qualquer vestígio de solvente, o filme deverá ser ainda colocado sob vácuo durante cerca de $12 \mathrm{~h}$.

A hidratação do lípido é feita adicionando ao balão contendo o filme, o volume desejado da solução aquosa escolhida, previamente aquecida a temperatura acima da(s) temperatura(s) de transição de fase do(s) fosfolípido(s). De modo a conseguir o desprendimento total do lípido das paredes do balão, deve-se alternar agitação com aquecimento da suspensão em banho a temperatura superior à transição de fase. A agitação deve ser feita com cuidado, de modo a não permitir a formação de espuma, o que iria alterar a concentração lipídica da suspensão de lipossomas final. Para tal, as agitações iniciais devem ser feitas manualmente, em círculos lentos, aumentando de intensidade em cada ciclo de aquecimento/agitação, até permitir a utilização de vortex. No fim desta etapa, dispõe-se já de uma suspensão de MLV. Contudo, de modo a possibilitar o equilíbrio das concentrações de solutos entre as várias lamelas, poderá ser conveniente a realização de cerca de oito ciclos de congelação da suspensão em azoto líquido e descongelação em banho de água a temperatura acima da(s) transição(ões) de fase do(s) fosfolípido(s) ${ }^{54}$.

A obtenção de vesículas unilamelares grandes e pequenas (LUV e SUV) tem como base a utilização de uma suspensão de vesículas multilamelares, preparada pelo processo acima descrito. Os métodos de preparação de LUV e SUV diferem essencialmente na sua fase final. Enquanto que, para a obtenção de SUV, os MLV passam por uma fase de sonificação de potência, na preparação de LUV recorre-se a um processo de extrusão $0^{55}$. Para esse fim, recorre-se a um extrusor ("extruder") ou a uma prensa de French ("French press"). $\mathrm{O}$ extrusor deve ser termostatizado (e.g., por circulação interna de água), mantendo-se a temperatura superior à da transição de fase $\mathrm{e}^{56,57}$. A extrusão é feita sob pressão de azoto, a aproximadamente 30 bar (o efeito da pressão empregue nas propriedades dos LUV é descrito na ref. 58), através de filtros com poros de $100 \mathrm{~nm}$ de diâmetro (usualmente de policarbonato). Previamente à introdução da amostra, e após a montagem do extrusor com os filtros, é conveniente efectuar uma a três extrusões apenas com a solução aquosa utilizada. Para a obtenção da suspensão de LUV, é recomendável a realização de dez ciclos de aquecimento da suspensão lipídica acima da temperatura de transição de fase (em banho de água ou no próprio extrusor), seguido da sua extrusão. Para certas amostras, bem como para concentrações elevadas de lípido, podem-se tornar necessárias algumas extrusões prévias utilizando filtros de poro mais largo (e.g., $400 \mathrm{~nm})$.

Na preparação de SUV, é desnecessária a realização do ultimo passo do processo de preparação de MLV (ciclos de congelação e descongelação). Para a sua conversão em SUV, os MLV são sujeitos a 7 a 10 ciclos de sonificação de potência (usualmente com sonificadores com ponta de titânio) durante $1 \mathrm{~min}$, seguida de $3 \mathrm{~min}$ de paragem, de modo a permitir o arrefecimento da amostra em água fria ou gelo. Após as sonificações, a suspensão lipídica deverá estar (quase) totalmente límpida. De seguida, esta é mantida em repouso durante $1 \mathrm{~h}$, em banho de água a temperatura acima da transição de fase, para o processo de recozimento ("annealing"), destinado a eliminar defeitos nas bicamadas resultantes da sonificação $0^{59}$. Finalmente, a amostra tem que ser centrifugada a $10000 \mathrm{~g}$ e aproximadamente $25^{\circ} \mathrm{C}$, durante $15 \mathrm{~min}$, de modo a sedimentar as partículas de titânio libertadas da ponta do sonificador, aproveitando-se apenas o sobrenadante. Se a sonificação tiver sido insuficiente ou ineficiente, aparecerá um pequeno precipitado branco, de lípido, sobre o precipitado negro do metal.

As suspensões de LUV ou SUV deverão ser usadas até 24 h após a sua preparação. As vesículas deverão ser guardadas a $4{ }^{\circ} \mathrm{C}$, até próximo da sua utilização.

Consoante o objectivo pretendido, podem ser introduzidas várias alterações aos processos de preparação descritos (para revisão ver, e.g., ref. 27). Em detrimento da evaporação do solvente, a secagem do lípido pode também ser conseguida por sublimação do solvente ou secagem em "spray". A secagem pode mesmo ser desnecessária, recorrendo-se à injecção directa da solução de lípido, em solvente orgânico, na fase aquosa (podendo as fases serem ou não miscíveis). O solvente orgânico é depois eliminado por evaporação, diálise, ultrafiltração ou cromatografias.

Nas outras fases da preparação de vesículas lipídicas podem também ser introduzidas importantes alterações. Nomeadamente, na pre- 
paração de SUV, a substituição da sonificação de potência por vesiculação espontânea (existente aquando da hidratação de certas misturas de fosfolípidos sob condições controladas) ou por extrusão através de filtros com poros de diâmetro da ordem dos $30 \mathrm{~nm}$; solubilização com detergentes, seguida da sua remoção (método utilizado para a preparação de LUV com proteínas de membrana); reorganização em LUV de MLV formados por alguns fosfolípidos de carga negativa, através de uma variação transiente de $\mathrm{pH}$; ou a formação de lipossomas maiores a partir da fusão induzida de vesículas lipídicas de menores dimensões ${ }^{27}$.

\section{Aplicação}

Conforme indicado na Figura 1, os lipossomas adquiriram uma larga aceitação, tanto em disciplinas de Ciência fundamental, como em áreas mais aplicadas. No que se refere a Ciência fundamental, a utilização de lipossomas como sistemas modelo de membranas está largamente consagrada, tendo resultado destes estudos a publicação de milhares de artigos científicos. LUV, SUV e MLV são os sistemas de vesículas mais utilizados, sendo ainda de referir a importância e aplicabilidade dos GUV para estudos de microscopia, nomeadamente recorrendo a técnicas de microscopia de fluorescência ${ }^{51,60}$. Os lipossomas são também de grande utilidade em estudos de QuímicaFísica de lípidos ${ }^{61}$, formação de domínios lipídicos em membranas ${ }^{62}$, interacções celulares ${ }^{42}$ e deformabilidade de sistemas lipídicos ${ }^{63}$.

Nos estudos de aplicação mais imediata, o fulcro do interesse científico tem-se situado na sua utilização como sistemas transportadores. Contudo, a sua utilização em outras aplicações Biomédicas (e.g., testes diagnósticos, transfusões sanguíneas na ausência de dador apropriado, desintoxicação através da utilização de agentes quelantes), industriais (existem nos nossos dias várias empresas dedicadas exclusivamente à produção de formulações de lipossomas para utilização de grandes grupos empresariais multinacionais), cosméticas (regeneração e hidratação do estrato córneo e parte viva da epiderme), agrícolas (estabilização de fertilizantes), pecuárias (maturação de lacticínios) e em processos de purificação, recuperação, catálise ou conversão de energia tem tido, igualmente, uma importância considerável 18,19,44-46,49.

Uma das principais vantagens da utilização de lipossomas como transportadores é a facilidade de incorporação de um fármaco, independentemente da sua carga ou massa molecular. Para além disso, os sistemas de vesículas lipídicas encontram-se já bastante bem caracterizados em termos de Química-Física, estrutura, estabilidade, toxicidade, imunogenicidade e formas de administração in vivo (intravenosa, intramuscular, subcutânea, dérmica, ocular, pulmonar, nasal ou oral), dispondo-se de um vasto leque de possibilidades na escolha do sistema mais adequado para cada fim $^{49}$.

Contudo, embora os resultados obtidos in vitro sejam encorajadores, a aplicação de lipossomas in vivo está limitada pela sua retenção ao nível do sistema retículo-endotelial, para além da sua falta de especificidade ${ }^{12}$. Na maioria das suas aplicações, as vesículas lipídicas, como qualquer outro sistema coloidal estranho ao organismo, são expostas a vários agentes específicos e não específicos, que tendem a reduzir a sua presença. Embora esta eliminação seja, em geral, consideravelmente mais lenta que no caso de um fármaco livre, compromete seriamente muitas das suas aplicações ${ }^{50}$.

\section{VESÍCULAS LIPÍDICAS ESTABILIZADAS}

No que se refere a lipossomas utilizados como sistemas transportadores de fármacos, alguns autores fazem a distinção entre um "transporte passivo", em que os lipossomas se direccionam no organismo de acordo com o seu padrão de distribuição natural, sendo constituídos apenas por fosfolípidos ou fosfolípidos e esteróis, e um "transporte activo", em que se tentam modificar os padrões de distribuição natural dos lipossomas, através de alterações na sua estrutura e composição ${ }^{64}$.

Apesar das limitações práticas da utilização de lipossomas como sistemas transportadores de fármacos, a utilização de vesículas lipídicas continua a ter grandes vantagens relativamente a outras famílias de transportadores (vide supra). Os problemas existentes levaram ao desenvolvimento de sistemas lipídicos modificados (essencialmente pela inserção de certas moléculas na sua camada exterior), com novas possibilidades de "transporte activo" e o objectivo de evitar a sua eliminação pelo sistema retículo-endotelial. Os sistemas deste tipo foram designados genericamente por lipossomas furtivos ("stealth liposomes"), embora o termo não esteja totalmente consagrado $^{50}$. Para outros autores ${ }^{49}$ a distinção é feita de outro modo, sendo os sistemas de vesículas lipídicas divididos em lipossomas de primeira geração (convencionais) e de segunda geração (subdivididos em lipossomas furtivos, catiónicos e direccionados ou imunolipossomas). Tendo em conta que a principal limitação dos lipossomas convencionais é a sua eliminação de circulação pelo sistema retículo-endotelial, Lasic e Needham ${ }^{50}$ definem arbitrariamente lipossomas furtivos como sistemas lipídicos modificados com um tempo de meia vida em circulação (tempo necessário para que a sua concentração seja reduzida a metade) superior a 2 h. Contudo, podem-se obter com lipossomas furtivos tempos de meia vida em circulação 100 vezes superiores aos dos lipossomas convencionais ${ }^{65}$.

Os métodos de modificação experimentados na alteração dos lipossomas convencionais de modo a reduzir a sua eliminação incluíram a sua associação com anticorpos específicos para determinadas células ${ }^{66}$, revestimento com imunoglobinas M (IgM) agregadas por aquecimento ${ }^{67}$, ligação covalente de anticorpos ${ }^{68}$, ou por incorporação de lípidos imunogénicos ${ }^{69}$, glicoproteínas ${ }^{70}$, glicolípidos naturais $^{71}$ e glicolípidos sintéticos ${ }^{72}$. Alguns destes métodos de modificação já se mostraram úteis na preparação de transportadores para aplicações biomédicas, nomeadamente terapia génica, quimioterapia e direccionamento de lipossomas para células, orgãos ou tecidos específicos ${ }^{65}$.

As várias aproximações possíveis à elaboração de sistemas de vesículas lipídicas estabilizadas têm sido descritas em diversos artigos de revisão, alguns dos quais centrados em aproximações específicas $^{43,50,64,65,73-80}$.

\section{CONCLUSÃO}

Os lipossomas e sistemas com eles aparentados permitiram uma forma simples e rápida mas apenas moderadamente eficaz de transporte in vivo de fármacos. O desenvolvimento continuado de vesículas modificadas tem levado a melhorias significativas na sua prestação. A bala mágica de Ehrlich vai-se aproximando do centro do alvo.

\section{AGRADECIMENTOS}

O presente trabalho foi parcialmente financiado pela Fundação para a Ciência e Tecnologia do Ministério da Ciência e Tecnologia (Portugal) e pela Fundação Calouste Gulbenkian (Portugal).

\section{REFERÊNCIAS}

1. Ehrlich, P. Em Collected Studies on Immunology; Ehrlich, P., ed.; John Wiley \& Sons: Londres, 1906, p. 404-442.

2. Cammas, S.; Kataoka, K. Em Solvents and Self-Organization of Polymers; Webber, S.E.; Munk, P.; Tuzar, Z., eds.; Kluwer Academic Publishers: Dordrecht, 1996, p. 83-113.

3. Jankun, J. Em Targeting of Drugs 4. Advances in System Constructs; Gregoriadis, G.; McCormack, B.; Poste, G., eds.; Plenum Press: Nova York, 1994, p. 67-79. 
4. Chang, T. M. S.; Science 1964, 146, 524.

5. Chang, T. M. S.; Nature 1971, 229, 117.

6. Chang, T. M. S.; Poznansky, M. J.; Nature 1968, 218, 243.

7. Bangham, A. D.; Standish, M. M.; Watkins, J. C.; J. Mol. Biol. 1965, 13, 238.

8. Sessa, G.; Weissmann, G.; J. Lipid Res. 1968, 9, 310

9. Stoeckenius, W.; J. Biochem. Biophys. Cytol. 1959, 5, 491.

10. Sessa, G.; Weissmann, G.; J. Biol. Chem. 1970, 245, 3295.

11. Gregoriadis, G.; Leathwood, P. D.; Ryman, B.E.; FEBS Lett. 1971, 14, 95.

12. Gregoriadis, G.; The Biochemist 1994, Feb./Mar., 8.

13. Lasic, D.; Am. Scientist 1992, 80, 20.

14. Van Berkel, T. J. C.; De Smidt, P. C.; Van Dijk, M. C. M.; Ziere, G. J.; Bijsterbosch, M. K.; Biochem. Soc. Trans. 1990, 18, 748.

15. Vyas, S. P.; Jaitely, V.; Kanaujia, P.; Pharmazie 1997, 52, 259.

16. Tyrrell, D. A.; Heath, T. D.; Colley, C. M.; Ryman, B.E.; Biochim. Biophys. Acta 1976, 457, 259.

17. Ostro, M. J.; Sci. Am. 1987, 256, 91.

18. Lichtenberg, D.; Barenholz, Y.; Methods Biochem. Anal. 1988, 33, 337.

19. Lasic, D. D.; Trends Biotechnol. 1998, 16, 307.

20. Bangham, A. D. Em Permeability and Function of Biological Membranes; Bolis, L.; Katchalsky, A.; Keynes, R. D.; Lowenstein, W. R.; Pethica, B. A., eds.; North-Holland Publishing Company: Amsterdão, 1970, p. 195206.

21. Michalet, X.; Jülicher, F.; Fourcade, B.; Seifert, U.; Bensimon, D.; La Recherche 1994, 269, 1012.

22. Sackmann, E.; Feder, T.; Mol. Membr. Biol. 1995, 12, 21

23. Mouritsen, O. G.; Jørgensen, K.; Pharm. Res. 1998, 15, 1507.

24. Wortis, M.; Biol. Skr. Dan. Vid. Selsk. 1998, 49, 59.

25. Szoka, Jr., F.; Papahadjopoulos, D.; Annu. Rev. Biophys. Bioeng. 1980, 9 , 467

26. Hope, M. J.; Bally, M. B.; Mayer, L. D.; Janoff, A. S.; Cullis, P. R.; Chem Phys. Lipids 1986, 40, 89.

27. Woodle, M. C.; Papahadjopoulos, D.; Methods Enzymol. 1989, 171, 193.

28. New, R. R. C. Em Liposomes: A Practical Approach; New, R. R. C., ed.; Oxford University Press: Oxford, 1990, p. 33-104.

29. Lasic, D. D.; Biochem. J. 1988, 256, 1.

30. Papahadjopoulos, D.; Nir, S.; Düzgünes, N.; J. Bioenerg. Biomembr. 1990 , $22,157$.

31. Cullis, P. R.; Bally, M. B.; Madden, T. D.; Mayer, L. D.; Hope, M. J.; Trends Biotechnol. 1991, 9, 268.

32. New, R. R. C.; Ref. 28, p. 105-162.

33. Jones, G. R.; Cossins, A. R.; Ref. 28, p. 183-220.

34. Gregoriadis, G.; N. Engl. J. Med. 1976, 295, 765.

35. Papahadjopoulos, D.; Gabizon, A.; Ann. N.Y. Acad. Sci. 1987, 507, 64.

36. Juliano, R. L.; Trends Pharmacol. Sci. 1981, Feb., 39.

37. Hopkins, S. J.; Drugs Today 1981, 17, 43.

38. Gregoriadis, G.; Ref. 3, p. 113-118.

39. Allen, T. M.; Drugs 1998, 56, 747.

40. Cullis, P. R.; Fenske, D. B.; Biol. Skr. Dan. Vid. Selsk. 1998, 49, 201.

41. Mayer, L. D.; Bally, M. B.; Hope, M. J.; Cullis, P. R.; Chem. Phys. Lipids 1986, 40, 333 .

42. Margolis, L. B.; Biochim. Biophys. Acta 1984, 779, 161.

43. Kersten, G. F. A.; Crommelin, D. J. A.; Biochim. Biophys. Acta 1995, 1241, 117.

44. Sallovitz, J. M.; Menghini, M. I. Z.; Lanusse, C. E.; Vet. Res. 1998, 29, 409.

45. Winslow, R. M.; Annu. Rev. Med. 1999, 50, 337.
46. Chang, T. M. S.; Trends Biotechnol. 1999, 17, 61

47. Proença, M. C.; Martins e Silva, J.; Acta Méd. Port. 1983, 4, 1.

48. Cruz, M. E. M.; Futuro 1989, ano III, $n .^{\circ} 27,40$.

49. Cruz, M. E. M.; Bol. Biotecnol. 1997, 58, 3.

50. Lasic, D. D.; Needham, D.; Chem. Rev. 1995, 95, 2601

51. Bagattoli, L. A.; Gratton, E.; Biophys. J. 2000, 79, 434.

52. Liu, F.; Sugar, I.P.; Chong, P. L.-G.; Biophys. J. 1997, 72, 2243.

53. Castanho, M. A. R. B.; Prieto, M.; Jameson, D.M.; Biochim. Biophys. Acta 1999, 1419, 1

54. Mayer, L. D.; Hope, M. J.; Cullis, P. R.; Janoff, A.S.; Biochim. Biophys. Acta 1985, 817, 193.

55. Hope, M. J.; Bally, M. B.; Webb, G.; Cullis, P. R.; Biochim. Biophys. Acta 1985, 812,55 .

56. Mayer, L. D.; Hope, M. J.; Cullis, P. R.; Biochim. Biophys. Acta 1986, 858, 161.

57. Nayar, R.; Hope, M. J.; Cullis, P. R.; Biochim. Biophys. Acta 1989, 986, 200

58. Hunter, D. G.; Frisken, B. J.; Biophys. J. 1998, 74, 2996.

59. Lawaczeck, R.; Kainosho, M.; Chan, S. I.; Biochim. Biophys. Acta 1976, $443,313$.

60. Haverstick, D. M.; Glaser, M.; Proc. Natl. Acad. Sci. U.S.A. 1987, 84, 4475.

61. Fendler, J. H.; Membrane Mimetic Chemistry, John Wiley \& Sons: Nova York, 1982, p. 121-158.

62. Glaser, M.; Comments Mol. Cell. Biophys. 1992, 8, 37.

63. Heinrich, V.; Bozic, B.; Svetina, S.; Zekš, B.; Biophys. J. 1999, 76, 2056.

64. Sunamoto, J.; Iwamoto, K.; CRC Crit. Rev. Therapeutic Drug Carrier Systems 1986, 2, 117.

65. Cohen, S.; Langer, R.; J. Liposome Res. 1995, 5, 813

66. Gregoriadis, G.; Neerunjun, E. D.; Biochem. Biophys. Res. Commun. 1975, $65,537$.

67. Weissmann, G.; Bloomgarden, D.; Kaplan, R.; Cohen, C.; Hoffstein, S.; Collins, T.; Gotlieb, A.; Nagle, D.; Proc. Natl. Acad Sci. U.S.A. 1975, 72, 88.

68. Torchilin, V. P.; Khau, B. A.; Smirnov, V. N.; Haber, E.; Biochem. Biophys. Res. Commun. 1979, 89, 1114.

69. Weinstein, J. N.; Blumenthal, R.; Sharrow, S. O.; Henkart, P.A.; Biochim. Biophys. Acta 1978, 509, 272.

70. Banno, Y.; Ohki, K.; Nozawa, Y.; Biochem. Int. 1983, 7, 455.

71. Spanjer, H. H.; Scherphof, G.L.; Biochim. Biophys. Acta 1983, 734, 40.

72. Mauk, M. R.; Gamble, R. C.; Baldeschwieler, J. D.; Science 1980, 207, 309.

73. Sunamoto, J.; Sato, T. Em Multiphase Biomedical Materials; Tsuruta, T.; Nakajima, A., eds.; VSP: Utrecht, 1989, p. 167-190.

74. Gupta, R. K.; Relyveld, E. H.; Lindblad, E. B.; Bizzini, B.; Ben-Efraim, S.; Gupta, C. K.; Vaccine 1993, 11, 293.

75. Huang, L.; J. Liposome Res. 1994, 4, 397.

76. Lohmann, D.; Macromol. Symp. 1995, 100, 25.

77. Desormeaux, A.; Bergeron, M. G.; J. Drug Target 1998, 6, 1.

78. Santos, N. C.; Prieto, M.; Morna-Gomes, A.; Betbeder, D.; Castanho, M. A. R. B.; Biopolymers 1997, 41, 511.

79. Santos, N. C.; Sousa, A. M. A.; Betbeder, D.; Prieto, M. J. E.; Castanho, M. A. R. B.; Carbohydr. Res. 1997, 300, 31.

80. Castanho M. A. R. B.; Prieto, M. J. E.; Betbeder, D.; Santos, N. C. Em Light Scattering and Photon Correlation Spectroscopy; Pike, R.; Abbiss, J. B., eds.; Kluwer: Dordrecht, 1997, p. 173-187. 